\title{
The need for operational research and capacity-building in support of the Global Technical Strategy for Malaria 2016-2030
}

\author{
Andrew Ramsay ${ }^{*}$, Piero Olliaro and John C. Reeder
}

The Global Technical Strategy for Malaria 2016-2030 was adopted by the 68th World Health Assembly in May 2015. It emphasizes the importance of scaling up malaria control responses and moving towards elimination [1]. It is anticipated that such scale-up will help countries reduce and, eventually, eliminate the human suffering caused by malaria as well as contribute more broadly to the achievement of the Sustainable Development Goals.

The Global Technical Strategy consists of three main pillars, underpinned by two supporting elements (Fig. 1). The first of the supporting elements, harnessing innovation and expanding research, is also recognized as critical in the global control and elimination of other diseases, such as tuberculosis [2]. It is recognized that operational and implementation research are needed to ensure that existing interventions are applied effectively and efficiently in different contexts and, as new interventions become available, to ensure that innovation is deployed appropriately and to maximum effect.

In 2011, the malERA Consultative Group on Health Systems and Operational Research published a Research Agenda for Malaria Eradication: Health Systems and Operational Research [3]. The WHO Global Malaria Programme (GMP) has more recently published the report of a multi-partner meeting that discussed operational challenges for malaria elimination, identified priority operational research questions and recommended ways forward [4]. Other organizations have produced similar lists of operational research priorities [5].

There is no shortage of recommendations on the priorities for operational research and most authors consider operational research to be relatively straightforward

\footnotetext{
${ }^{*}$ Correspondence: ramsaya@who.int

Special Programme on Research and Training in Tropical Diseases (TDR), a co-sponsored programme of UNICEF/UNDP/World Bank/WHO, based at the World Health Organization, Geneva, Switzerland
}

and, if using routinely-collected data, inexpensive. However, a recent review of the literature on malaria control and elimination between 2008 and 2013 (15,886 articles) revealed that less than $4 \%$ met the definition of operational research. Of these articles only 19 (3.8\%) were related to malaria surveillance [6]. It would seem that operational research, though recognized as critically important to the success of global strategies for malaria control and elimination, is not so commonly undertaken or at least not so commonly published. Indeed, it could be argued that the difference between these two is academic since unpublished research is unlikely to inform widespread scaling up of malaria activities. Why is so little operational research done when much of it would be straightforward and inexpensive and could be done within the context of routine malaria programme activities?

It is a long-standing problem. In 2007, a report of the Global Fund's Technical Review Panel noted that operational research was often absent or inadequately elaborated in proposals [7]. The report further stated that proposals clearly described bottlenecks to progress and that these provide the basis for operational research questions that seem obvious but were not proposed.

How can operational research be promoted to support the new Global Technical Strategy for Malaria? A good start would be to look at the recent experiences of other disease control programmes. In 2011, the WHO listed its priorities in operational research to improve tuberculosis care and control. One of the five priority areas for operational research was capacity-building for operational research. Key questions included: what are the existing models of operational health research capacity? What is the impact of existing training models in terms of products, outputs and outcomes? How to ensure sustainable operational research capacity at the national level? 4 years later, its Global Action Framework for TB Research 


\begin{tabular}{|c|c|c|}
\hline \multicolumn{2}{|c|}{ WHO's Global Technical Strategy for Malaria 2016 - 2030 } \\
\hline Pillar I & Pillar 2 & Pillar 3 \\
\hline Ensure universal access to & Accelerate efforts towards & Transform malaria \\
malaria prevention, diagnosis & elimination and attainment of & surveillance into a core \\
and treatment & malaria-free status & intervention \\
\hline Supporting elements & \\
\hline 1. Harnessing innovation and expanding research \\
\hline 2. Strengthening the enabling environment
\end{tabular}

Fig. 1 The World Health Organization Global Technical Strategy for Malaria 2016-2030

described some of the lessons from this exercise and has provided case studies of how operational research capacity has been built in public health programmes in lowincome and middle-income countries [2]. One of these case studies was the Structured Operational Research and Training Initiative (SORT IT) a global partnership-based initiative led by the Special Programme for Research and Training in Tropical Diseases (TDR) based at WHO [8]. Started in 2012, SORT IT aims to support countries to: conduct operational research around their own priorities, build adequate and sustainable operational research capacity within public health programmes; and make evidence-informed improvements to programme implementation. More than 400 health workers in 80 countries have been trained through SORT IT to date. Over the course of 1 year, participating health workers learn the skills required to develop operational research questions, protocols, data capture and analysis instruments and to publish their work. Over $90 \%$ of participants publish their research in the peer reviewed literature and many go on to become facilitators in further SORT IT training courses. The training is currently being delivered in English, Russian and Spanish, with the transition into French underway. The model has been recognized as a reliable way to build the much-needed research capacity in public health programmes in LMICs $[9,10]$.

Having its roots in a training course run by Médecins Sans Frontières and the International Union Against Tuberculosis and Lung Diseases, that supported tuberculosis control, SORT IT is now delivering regional and national capacity-building for operational research in all WHO regions and in number of disease areas $[11,12]$. In TDR-supported SORT IT Programmes, the core training course is embedded within broader capacity-building activities in knowledge management (research needs assessments and prioritization, dissemination of research findings and evidence-informed policy making). Efforts are also made to consolidate research capacity that has been built through SORT IT by providing participants with further research training and small research grants.

In 2014, two research studies related to malaria elimination were supported by SORT IT [13, 14]. In 2015-16, in collaboration with the Global Malaria Programme and the WHO African Regional Office (AFRO), a SORT IT programme supported four malaria-eliminating countries in Southern Africa: Botswana, Namibia, South Africa and Swaziland. A Supplement of Malaria Journal is in preparation to feature research outputs of this SORT IT programme. It is hoped that this Supplement will encourage others to adopt approaches like SORT IT, conduct operational research while building research capacity in malaria programmes and make evidence-informed improvements to policy and practice.

On the occasion of the 2016 World Malaria Day the authors would like to highlight both the need for, and the feasibility of, building operational research capacity in malaria programmes in low- and middle-income countries if the ambitions of the Global Technical Strategy for Malaria 2016-2030 are to be achieved.

\section{Authors' contributions}

AR drafted the core commentary, with input from PO and JCR. All authors read and approved the final manuscript.

\section{Competing interests}

The authors declare that they have no competing interests. SORT IT programme mentioned is supported by TDR.

Received: 18 April 2016 Accepted: 19 April 2016

Published online: 25 April 2016 


\section{References}

1. WHO. Global technical strategy for malaria 2016-2030. Geneva: World Health Organization; 2015.

2. WHO. Global action framework for research in support of the third pillar of WHO's End TB Strategy. Geneva: World Health Organization; 2015.

3. The malERA Consultative Group on health Systems and. Operational Research. A Research Agenda for Malaria Eradication: Health Systems and Operational Research. PLoS Med. 2011;8:e1000397.

4. WHO. Planning meeting for operational research on malaria elimination. Geneva: World Health Organization; 2014.

5. President's Malaria Initiative. Strategic guidance for operational research; 2014.

6. Zhou SS, Rietveld AEC, Velarde-Rodriguez M, Ramsay AR, Zhang SS, Zhou $\mathrm{XN}$, et al. Operational research on malaria control and elimination: a review of projects published between 2008 and 2013. Malar J. 2014;13:73.

7. The Global Fund to Fight AIDS, Tuberculosis and Malaria. Report of the Technical Review Panel and the Secretariat on Round 10 proposals. The Global Fund 22nd Board Meeting, Sofia; 2007.

8. Ramsay A, Harries AD, Zachariah R, Bissell K, Hinderaker SG, Edginton $M$, et al. The Structured Operational Research and Training Initiative (SORT IT) for public health programmes. Public Health Action. 2014;4:79-84.
9. ESSENCE on Health Research. Seven principles for strengthening research capacity in low- and middle-income countries: simple ideas in a complex world. ESSENCE Good practice document series. Geneva: World Health Organization; 2014.

10. Quaglio GL, Ramsay A, Harries AD, Karapiperis T, Putoto G, Dye C, et al. Calling on Europe to support operational research in low-income and middle-income countries. Lancet Global Health. 2014;2:e308.

11. Public Health Panorama. Thematic Issue on Tuberculosis in Central Asia. January 2016. http://www.euro.who.int/_data/assets/pdf_ file/0020/304463/Panorama2-1-FULL.pdf?ua=1.

12. Pan American Journal of Public Health. January 2016. Thematic issue on Tuberculosis in the region of the Americas. http://www.paho.org/ journal/index.php?option=com_content $\&$ view $=$ article $\& i d=187 \% 3 \mathrm{Ajanu}$ ary-2016\&catid=698\%3Aspecial-issues\&lang=en

13. Zhou SS, Zhang SS, Zhang L, Rietveld AEC, Ramsay AR, Zachariah R, et al. China's 1-3-7 surveillance and response strategy for malaria elimination: is case reporting, investigation and foci response happening according to plan? Infect Dis Poverty. 2015;4:55.

14. Velarde-Rodriguez M, Van den Bergh R, Fergus C, Casellas A, Sanz S, Cibulskis R, et al. Origin of malaria cases: a 7-year audit of global trends in indigenous and imported cases in relation to malaria elimination. Global Health Action. 2015;8:29133.

\section{Submit your next manuscript to BioMed Central and we will help you at every step:}

- We accept pre-submission inquiries

- Our selector tool helps you to find the most relevant journal

- We provide round the clock customer support

- Convenient online submission

- Thorough peer review

- Inclusion in PubMed and all major indexing services

- Maximum visibility for your research

Submit your manuscript at www.biomedcentral.com/submit
() Biomed Central 